\title{
Achieving Health Equity by Normalizing Cardiac Care
}

\author{
Cheryl Pegus, ${ }^{1, \dagger}$ lan Duncan, ${ }^{2, *}$ Judy Greener, Juan F. Granada, and Tamim Ahmed ${ }^{3}$
}

\begin{abstract}
Purpose: It is well known that minority patients, and particularly African Americans undergo lower rates of cardiac procedures than the white population, even when covered by equivalent insurance.

Methods: We analyzed the rates of percutaneous transluminal coronary angioplasty (PTCA) for acute myocardial infarction (AMI) and for intermediate coronary syndrome (ICS), and rates of transcatheter aortic valve replacement for aortic stenosis in the 2012-2013 Medicare Limited Data Set (5\% sample) file.

Results: Although blacks have similar prevalence rates for AMI and ICS, they experience lower PTCA rates when compared with that of white patients (10.57 vs. 19.40,-46\%). "Normalizing" procedure rates in the African American community to match their disease prevalence will require education and participation of all stakeholders: patients, providers, manufacturers, insurers, and advocacy organizations. Beyond improved clinical outcomes, financial incentives to "normalize care" exist. We estimate "lost" revenue within the Medicare population as a result of the lower procedure rates, at $\sim \$ 90$ million annually (\$22.0 million AMI, $\$ 9.4$ million ICS and \$68.7 million aortic valve disease).

Conclusions: Providing evidence-based care to all patients improves health equity and can lower downstream high-cost conditions such as heart failure and multiple repeat inpatient admissions. As we move toward valuebased care, the opportunity to normalize treatment for everyone seeking care is within our data analytics, innovative and collective reach.
\end{abstract}

Keywords: acute myocardial infarction; aortic stenosis; intermediate coronary syndrome; Medicare; percutaneous transluminal coronary angioplasty; transcatheter aortic valve replacement

\section{Introduction}

In cardiovascular disease, inequities in the quality and type of treatment made available to racial and ethnic minorities have been well documented. ${ }^{1}$ Over a decade ago, Unequal Treatment: Confronting Racial and Ethnic Disparities in Health Care, published by the Institute of Medicine (IOM, 2002 $2^{2}$ ), highlighted existing disparities in care. In particular, the report identified the lower rate of necessary cardiovascular proceduresup to $50 \%$ lower-performed on black compared to white patients. The IOM findings led to a greater focus on addressing racial and ethnic disparities and initiated more aggressive funding and programming by both public and private organizations. ${ }^{3}$ The quality of cardiovascular care for both blacks and whites has since improved; from 2004 to 2014, cardio-vascular disease (CVD)-attributable death rates for all adults dropped by $25.3 \%$ and the actual number of CVD deaths decreased $6.7 \%{ }^{4}$

Together with the decline in mortality, there has been a tightening in the gap between white and black patients on some CVD clinical outcomes, particularly

\footnotetext{
${ }^{1}$ Caluent, Inc., Philadelphia, Pennsylvania.

${ }^{2}$ Department of Statistics and Applied Probability, University of California, Santa Barbara, Santa Barbara, California.

${ }^{3}$ Inside Edge Consulting.

${ }^{4}$ Cardiovascular Research Foundation, Columbia University Medical Center, New York, New York.

${ }^{5}$ Santa Barbara Actuaries, Inc., Santa Barbara, California.

${ }^{\dagger}$ Present address: Regence/Cambia Health Solutions, Portland, Oregon.
}

*Address correspondence to: lan Duncan, FSA, FIA, FCIA, FCA, CSPA, MAAA, Department of Statistics and Applied Probability, University of California, Santa Barbara, Santa Barbara, CA 93105, E-mail: duncan@pstat.ucsb.edu

(C) Cheryl Pegus et al. 2018; Published by Mary Ann Liebert, Inc. This Open Access article is distributed under the terms of the Creative Commons License (http://creativecommons.org/licenses/by/4.0), which permits unrestricted use, distribution, and reproduction in any medium, provided the original work is properly cited. 
the rates of death attributable to CVD. ${ }^{5,6}$ Significant disparities continue to be evident however. A recent report from the Centers for Disease Control and Prevention indicates that cardiovascular-related mortality has dropped more slowly for black individuals $(2.2 \%$ per year) than for whites $(2.4 \%$ per year) for the full study period of 1998-2015. The overall rate of decline for both black and white patients before 2010 (3.4\% and $3.9 \%$ respectively) decelerated after 2010 and has leveled for both groups to $\sim 1.0 \%$. Current data demonstrate that the disparity in heart disease death rates is still substantial and shows a $16.3 \%$ increase in the black-white mortality ratio from 1968 to 2015 . $^{7}$

The continued gap in life expectancy between black and white patients can be largely attributed to cardiovascular-related mortality. ${ }^{5,8}$ This is particularly salient when considering the changing demographics in the United States. The Census Bureau reports that close to $38 \%$ of the current population belongs to minority groups, with blacks and Hispanics making up the largest proportions. Census data projects that these populations will continue to grow and predominate by 2045 (https://census.gov/programs-surveys/ popproj/data/tables.2017.html). It is, therefore, increasingly critical to focus delivery of care on these populations with CVD.

\section{What is known about procedure disparities}

Decades of research have observed that blacks are less likely to receive beneficial, evidence-based cardiovascular interventions, and have less access to higher-cost invasive procedures, even when controlling for health insurance access. Studies conducted in the 1990s comparing procedure rates for cardiac catheterization, percutaneous coronary intervention (percutaneous transluminal coronary angioplasty [PTCA]), coronary artery bypass graft (CABG), and implantation of defibrillators demonstrated that black patients were less likely to undergo these procedures. ${ }^{9,10}$

More recent studies continue to demonstrate lower rates of cardiac interventions among black patients than white patients. ${ }^{11}$ Cram et al. found that blacks hospitalized with acute myocardial infarction (AMI) were significantly less likely to receive revascularization when compared with whites. ${ }^{12}$ Similarly, Albert et al. identified that the odds of receiving coronary revascularization in black patients is $30 \%$ lower than white patients. ${ }^{13}$ Black patients continue to be less likely to receive other effective treatments such as percutaneous coronary intervention, CABG, and implantation of de- fibrillators. ${ }^{12,14-16}$ A recent study found that blacks were about half as likely to be referred for cardiothoracic surgery as whites. ${ }^{17}$

The differences described are present even when factors such as age, coronary disease severity, comorbid conditions, insurance status, and site of care are controlled. ${ }^{12,14,16}$ A 2014 study of Medicare hospital claims data from 1992 to 2010 found that although differences in procedure rates had declined over time, rates of all procedures (angiography, PCTA, and CABG) were lower for blacks than whites throughout the study period. Even when adjusted for age and comorbidity, racial disparities remained significant.

Other cardiac conditions beyond coronary artery disease also show disparities in evidence-based treatment. Although data on the prevalence of severe aortic stenosis is limited, prevalence of the condition in blacks appears to be lower than for whites $(1.51 \%$ vs. $0.55 \%$, respectively). ${ }^{18}$ Controlling for this, however, blacks are less likely to receive aortic valve replacement (AVR). A recent study evaluating patients who met the criteria for AVR between 1999 and 2013 demonstrated that a lower proportion of black patients had surgical valve replacement (SAVR) $(26.6 \%)$ compared with white patients $(40.3 \%) .{ }^{18}$ Similarly, a study evaluating patients diagnosed between 2004 and 2010 found that the proportion of blacks receiving SAVR was significantly lower than for whites (39\% vs. $53 \%) .{ }^{19}$ A small study of 67 patients focused on transcatheter aortic valve replacement (TAVR) found that blacks were significantly less likely to receive TAVR than nonblacks ( $7 \%$ and $92 \%$ respectively) ${ }^{20}$ In a recent article, Holmes et al. estimated that in the years 2012-2015, $3.8 \%$ of black patients received this therapy compared with $93 \%$ in whites. ${ }^{21}$ It is important to note that although blacks are typically higher-risk patients, when treated with AVR, 1 year and 3-year survival has been found to be similar. ${ }^{18,19}$ Importantly, black patients referred for TAVR shared similar risks and outcomes when compared with a white population. ${ }^{22}$

\section{Study}

We analyzed 2012-2013 Medicare data for specific cardiac procedures performed by interventional cardiologists to determine rates of PTCA for AMI and intermediate coronary syndrome (ICS) and rates of TAVR for aortic valve disease (AVD). Our focus on this population of cardiac physicians is intended to isolate the procedures themselves particularly in the acute setting of AMI and ICS and because the procedures 
Table 1. Eligible Population

\begin{tabular}{lcc}
\hline Sample selections & 2012 & $\mathbf{2 0 1 3}$ \\
\hline All members & $2,674,799$ & $2,758,260$ \\
Exclude: Part A and Part B coverage & $(449,725)$ & $(458,563)$ \\
$\quad<10$ months/year & \multicolumn{1}{c}{$\begin{array}{l}(658,023) \\
\text { Exclude HMO coverage }\end{array}$} & $\begin{array}{l}(719,505) \\
\text { Final sample (annual) }\end{array}$ \\
$\begin{array}{l}\text { Final sample-unique members in } \\
\quad \text { years 2012-2013 }\end{array}$ & \multicolumn{2}{c}{$1,715,270$} \\
\hline
\end{tabular}

HMO, Health Maintenance Organization.

occur primarily in a hospital, removing access to ambulatory sites and referring physician networks as a confounding factor. Our focus is on patients who have Medicare fee-for-service as their primary insurance, controlling for the "access to insurance" variable.

Data

Data from the Medicare 5\% Limited Data Set (LDS) files were used in this analysis. The LDS file consists of de-identified beneficiary information in addition to institutional and noninstitutional claims. Institutional claims include claims from inpatient hospital, outpatient facility, skilled-nursing facility, and hospice facility sources. Noninstitutional files include information from physicians. The 5\% files do not include outpatient drug claims. Information about patient demographics is contained in the denominator files.

We eliminated patients who did not have Parts A and $B$ coverage in the denominator file for at least 10 months in each year, and members with Health Maintenance Organization (HMO) (Medicare Advantage) coverage. The number of unique members in each year was reduced from an average of 2.7 million beneficiaries to 1.57 million beneficiaries each year due to the selections above. The number of unique members over the period 2012-2013 was $\sim 1.72$ million (Table 1 ).

\section{Methods}

Our hypothesis is that the procedure rates between races are the same, assuming the same diagnoses and given that all patients have the same insurance coverage. Table 2 shows procedures for three conditions: AMI, ICS, and AVD. Appendix 1 shows the algorithms used to identify patients with different conditions. Note that the number of patients displayed in Table 3 is the number of unique patients with the specific diagnosis in 2012 and 2013. Because individuals entering Medicare are diagnosed and die continuously, we measure the number of months that a patient is observed over the 24-month period with the specific diagnosis. The number of mem-
Table 2. Procedures for Heart Conditions

\begin{tabular}{|c|c|}
\hline Condition & Procedures \\
\hline $\begin{array}{l}\text { Acute myocardial } \\
\text { infarction (AMI) } \\
\text { or } \\
\text { Intermediate } \\
\text { coronary } \\
\text { syndrome (ICS) }\end{array}$ & $\begin{array}{l}\text { Percutaneous transluminal coronary angioplasty } \\
\text { for single major coronary artery } \\
\text { Percutaneous transluminal coronary angioplasty } \\
\text { each additional branch of a major coronary } \\
\text { artery branch } \\
\text { Percutaneous transcatheter placement of } \\
\text { intracoronary stent(s), with coronary angioplasty } \\
\text { when performed; single major coronary artery or } \\
\text { branch for AMI } \\
\text { Percutaneous transcatheter placement of } \\
\text { intracoronary stent(s) for single major coronary } \\
\text { artery or branch; each additional branch of a } \\
\text { major coronary artery for AMI }\end{array}$ \\
\hline $\begin{array}{l}\text { Aortic valve } \\
\text { disease (AVD) }\end{array}$ & $\begin{array}{l}\text { Transcatheter aortic valve replacement (TAVR) } \\
\text { with prosthetic valve; percutaneous femoral } \\
\text { artery approach for Aostenosis } \\
\text { Transcatheter aortic valve replacement (TAVR) with } \\
\text { prosthetic valve; transapical exposure (e.g., left } \\
\text { thoracotomy) Aostenosi } \\
\text { Transcatheter aortic valve replacement with } \\
\text { prosthetic valve; open axillary artery approach } \\
\text { Aostenosis } \\
\text { Transcatheter aortic valve replacement (TAVR) with } \\
\text { prosthetic valve; open iliac artery approach } \\
\text { Aostenosis } \\
\text { Transcatheter aortic valve replacement (TAVR) with } \\
\text { prosthetic valve; transaortic approach (e.g., } \\
\text { median sternotomy, mediastinotomy) Aostenosis }\end{array}$ \\
\hline
\end{tabular}

ber months is then converted to a number of equivalent member years by dividing by 12 . (The same procedure is applied by Centers for Medicare and Medicaid Services (CMS) to calculate equivalent member years-see ResDAC. $^{23}$ )

In Table 3 we calculate absolute numbers of procedures for different race/ethnicity groups using the relationship between that race's rate and the white rate per 1000. For example, the procedure rate for PTCA for whites diagnosed with AMI is 83.03 (per 1000 diagnosed patients per year) and that for blacks is 68.90 (per 1000 diagnosed patients per year), resulting in a rate ratio of $1.21(=83.03 / 68.90)$. A ratio greater than 1.00 implies that whites have a $21 \%$ higher procedure rate than blacks. The raw procedure count for blacks is 358. To experience an equivalent number of procedures to whites, blacks would require an additional 73 procedures $[=358 \times(1.21-1.00)]$.

\section{Results}

Although we conducted the comparisons between the white population and other races, we focused on comparing two groups-white versus black.

Table 2 shows procedures for three conditions: AMI, ICS, and AVD. 
For Acute AMI and ICS conditions, we focused on PTCA. There are four types of such procedures-(i) PTCA for single major coronary artery or branch for AMI, and (ii) PTCA for each additional branch of a major coronary artery, (iii) Placement of intracoronary stents for single major coronary artery or branch, and (iv) Placement of intracoronary stents for each additional branch of a major coronary artery for AMI. (For the codes to identify these procedures see Appendix A2.) We used the same code set for identifying PTCA for the ICS condition.

For AVD, we focused on identifying TAVR procedures: (i) TAVR with prosthetic valve; percutaneous femoral artery approach for AoStenosis, (ii) TAVR with prosthetic valve; open femoral artery approach Aostenosis, and (iii) TAVR with prosthetic valve; open axillary artery approach Aostenosis. (iv) TAVR with prosthetic valve; open iliac artery approach Aostenosis, and (v) TAVR with prosthetic valve; transaortic approach (e.g., median sternotomy, mediastinotomy) Aostenosis.

Procedure rates are based on 1000 diagnosed members per year. For AMI, the white PTCA procedure rate $(83.03 / 1000)$ is high relative to the black PTCA procedure rate (68.90/1000). A significant difference is also observed for the ICS condition where the procedure rate for whites $(73.97 / 1000)$ is statistically significantly higher, relative to the black rate $(63.17 / 1000)$. For the AVD condition we also found that the white procedure rate $(19.40 / 1000)$ is statistically significantly higher relative to the rates of blacks (10.57/1000).

In Table 3 we sum all relevant procedures (per Table 2) for each diagnosis and report the number of diagnosed patients by race, procedure rates per 1000 diagnosed patients, and the average cost per procedure.

Table 3. Procedure Rates and Costs by Race and by Condition

\begin{tabular}{|c|c|c|c|c|c|}
\hline Race & Conditions & $\begin{array}{c}\text { Unique } \\
\text { diagnosed } \\
\text { members }\end{array}$ & Procedures & $\begin{array}{l}\text { Procedure } \\
\text { rate per } \\
1000 / \text { year }^{a}\end{array}$ & $\begin{array}{c}\text { Procedure } \\
\text { cost }\end{array}$ \\
\hline Black & AMI & 3045 & 358 & $68.90^{* *}$ & $\$ 21,760$ \\
\hline White & AMI & 25,144 & 3618 & 83.03 & $\$ 19,848$ \\
\hline All & AMI & 29,251 & 4217 & 81.48 & $\$ 20,090$ \\
\hline Black & ICS & 2223 & 256 & $63.17^{* *}$ & $\$ 16,151$ \\
\hline White & ICS & 19,038 & 2630 & 73.97 & $\$ 15,248$ \\
\hline All & ICS & 22,084 & 3100 & 72.90 & $\$ 15,389$ \\
\hline Black & AVD & 5339 & 103 & $10.57^{* *}$ & $\$ 49,435$ \\
\hline White & AVD & 73,479 & 2643 & 19.40 & $\$ 42,329$ \\
\hline All & AVD & 81,109 & 2838 & 18.59 & $\$ 44,407$ \\
\hline
\end{tabular}

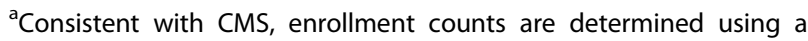
person-year methodology.

${ }^{*}$ Signifies $p<0.01$ level.

CMS, Centers for Medicare and Medicaid Services.

\section{Financial implications of under-provision} of procedures

The financial implications of differences in procedure rates are the work that we are highlighting in this article compared with previous studies that focused on procedure rates only. Table 5 shows the calculation to estimate underservice of procedures and its monetary magnitude. We estimated the under-provision of procedures in other races, assuming that other races experienced procedures at the same rate as the white population. We estimate the under-provision of procedures as:

Changes in procedures $=($ Procedure rate for white race

$$
\begin{aligned}
& \text { /Procedure rate black race) } \\
& \times \text { Total procedures for black race }
\end{aligned}
$$

In Table 3 we saw that procedure rates for PTCA for people with AMI was $68.90 / 1000$ for blacks versus $83.03 / 1000$ for whites. If black procedure rates were equal to those of whites, blacks would experience $20.5 \%$ more procedures, $(358 \times 0.205=73.38$ PTCA procedures over the 2-year period). Annually, we estimate an increase in procedures of $73.38 / 2$ or 36.69 additional procedures. Multiplying 36.69 additional procedures by the average cost per black patient procedure in the inpatient setting, $\$ 21,760$, we estimate reimbursement of the additional procedures as $\$ 798,403$. Table 5 shows that the result of normalizing the black procedure rate to be equal to that of the white population would increase reimbursement for this procedure by $\$ 798,403$ per year in 2012 2013 dollars. The table also shows estimates of the increase in revenue due to normalizing the underprovision of services for other two conditions.

As described previously, this analysis was conducted using the $5 \%$ sample file of the total Medicare population, excluding the Medicare Advantage (HMO) population. We can estimate the effect of normalizing procedure rates for all of Traditional (fee-for-service) Medicare by grossing up the $5 \%$ estimate. We can also make a rough estimate of the effect of normalization on the Medicare Advantage population using the relative

Table 4. Total Medicare Enrollment 2012-2013

\begin{tabular}{lcc}
\hline & \multicolumn{2}{c}{ 000,000's } \\
\cline { 2 - 3 } & Fee for service & Medicare advantage \\
\hline 2012 & 37.214 & 13.104 \\
2013 & 37.587 & 14.388 \\
Average & 37.401 & 13.746 \\
\hline
\end{tabular}


Table 5. Financial Effect of Normalizing Procedure Rates

\begin{tabular}{lccccccc}
\hline & & & & & & \multicolumn{3}{c}{ Estimated annual financial effect } \\
\cline { 7 - 8 } Race & Condition & $\begin{array}{c}\text { Total estimated } \\
\text { procedures }\end{array}$ & $\begin{array}{c}\text { Change in } \\
\text { procedures }\end{array}$ & Procedure cost & 5\% Sample & Traditional Medicare & Medicare advantage \\
\hline Black & AMI & 431.38 & 73.38 & $\$ 21,760$ & $\$ 798,403$ & $\$ 15,968,062$ & $\$ 6,003,991$ \\
Black & ICS & 299.74 & 43.74 & $\$ 16,151$ & $\$ 353,238$ & $\$ 6,845,743$ & $\$ 2,574,000$ \\
Black & AVD & 197.14 & 86.14 & $\$ 51,147$ & $\$ 2,203,023$ & $\$ 42,653,347$ & $\$ 16,037,658$ \\
All & & & & $\$ 3,354,664$ & $\$ 65,467,152$ & $\$ 24,615,649$ \\
\hline
\end{tabular}

Medicare Advantage and Traditional Medicare enrollments from 2012 to 2013. Relative enrollments from CMS reports are shown in Table 4, using data from the CMS Statistics Reports for $2013^{24}$ and $2014 .^{25}$ Estimated Medicare Advantage enrollment includes prepaid Medicare and Medicare Cost contract enrollment and excludes private fee-for-service, Programs of All-Inclusive Care for the Elderly (PACE), and so on. Average 2012-2013 Medicare Advantage enrollment represented $36.7 \%$ of Traditional Medicare enrollment.

In Table 5 we estimate the total undertreatment loss, based on evidence-based treatment to be $\$ 90$ million. Traditional Medicare represents $\$ 65.5$ million in total and Medicare Advantage a further \$24.6 million. These are necessarily estimates although they provide an idea of the financial effects of performing appropriate and life-saving procedures in under-served populations at the white population rate.

\section{Discussion: A Plan for Normalizing Care for Minority} Communities

The 2016 National Health care Quality and Disparities Report found that "while $20 \%$ of measures show disparities getting smaller for blacks and Hispanics, most disparities have not changed significantly for any racial and ethnic groups" ${ }^{26}$ With a focus on cardiac procedural care for blacks, our analysis shows inequities in the rate of cardiovascular procedures. Black patients experience fewer evidence-based treatments than whites, providers and cardiologists and other stakeholders face substantial "lost" opportunity to provide cost-effective care. Though improving clinical outcomes is incentive enough in a value-based world, financial incentives can provide greater impetus. "Normalizing" procedure rates among blacks to that of whites, consistent with their disease prevalence, will require engagement of all stakeholders using data-driven input and targeting measurable solutions.

Solutions that have the potential to help normalize procedure rates and decrease disparities include providing better and more regional and individual provider data, focusing on embedded electronic medical record (EMR) toolsets, and supporting patient understanding of treatment options. Cardiovascular registries that link to health insurance claims and/or EMR data can conceivably provide transparent information about treatment cost and quality for various racial and ethnic groups. These tools can guide physicians in their patient communication and treatment recommendations, improving consistency of appropriate cardiovascular procedures among patient groups.

Advocacy organizations like Association of Black Cardiologists (ABC), American College of Cardiology (ACC), American Hospital Association (AHA), and Cardiovascular Research Foundation (CRF) are positioned to drive awareness and educate both physicians and patients on specific aspects of cardiovascular care through directed programming and communication activities. ${ }^{27}$ Advocacy organizations can use their large member and communication networks to disseminate information and impact measurable change.

\section{Limitations}

This study has a number of limitations. The lower procedure rates demonstrated for black patients could be based on patient preference, which we were not able to ascertain. Race of the patients' cardiologist may impact the treatment decision and we did not have that information for our assessment. Black patients treated by a physician who looks like them may feel a greater sense of trust and have a heightened understanding of the health decisions to be made. ${ }^{28}$ The data presented here are from 2012 to 2013. There may have been improvements in treatment of blacks since that time. Finally, the costs used in the estimates presented here come from the CMS LDS data set; however, it is possible that these costs are not complete and may skew the estimates presented.

\section{Conclusion}

We find that, consistent with other studies, Black patients with cardiac conditions are under-served with respect to evidence-based procedures. We share the lost 
revenue of undertreatment in parallel, to place financial terms with this clinical cost. Across all Medicare patients we estimate that $\sim \$ 90$ million in revenue annually is lost by cardiologists as a result of the lower procedure rates. Normalizing care can significantly impact patients' lives today and decrease the long-term cost of more severe, chronic conditions.

\section{Statement of Informed Consent}

This study was a retrospective data analysis using a deidentified, publicly available database (The Medicare Limited Data Set). No informed consent was required.

\section{Statement of Human and Animal Rights}

This study was a retrospective data analysis using a deidentified, publicly available database (The Medicare Limited Data Set). Human and Animal rights are not applicable.

\section{IRB Waiver}

This retrospective study was performed entirely using an administrative claims dataset, the de-indentified Limited Data Set (5\% File) from CMS. No human subjects or identifiable data were involved in this study. IRB approval was not required in this circumstance.

\section{Author Disclosure Statement}

No competing financial interests exist.

\section{References}

1. Mozaffarian D, Benjamin EJ, Go AS, et al. Heart disease and stroke statistics - 2015 update: a report from the American Heart Association. Circulation. 2015;131:e29.

2. Nelson A. Unequal treatment: confronting racial and ethnic disparities in health care. J Natl Med Assoc. 2002;94:666-668.

3. Lewey J, Choudhry NK. The current state of ethnic and racial disparities in cardiovascular care: lessons from the past and opportunities for the future. Curr Cardiol Rep. 2014;16:530.

4. Benjamin EJ, Blaha MJ, Chiuve SE, et al. Heart disease and stroke statistics2017 update: a report from the American Heart Association. Circulation. 2017;135:e146.

5. Agency for Healthcare Research and Quality. National Healthcare Disparities Report 2012. AHRQ Publication No. 13-0003. Rockville, MD: Agency for Healthcare Research and Quality, 2013.

6. Go AS, Mozaffarian D, Roger VL, et al. Heart disease and stroke statistics2014 update: a report from the American Heart Association. Circulation. 2014;129:e28-e292.

7. Van Dyke $M$, Greer $S$, Odom $E$, et al. Heart disease death rates among blacks and whites aged $\geq 35$ years-United States, 1968-2015. MMWR Surveill. Summ. 2018;67(SS-5):1-11.

8. Macinko J, Elo IT. Black-white differences in avoidable mortality in the USA, 1980-2005. J Epidemiol Community Health. 2009;63:715-721.

9. McBean AM, Warren E, Babish JD. Continuing differences in the rates of percutaneous transluminal angioplasty and CABG surgery between elderly black and white Medicare beneficiaries. Am Heart J. 1994;287-295.

10. Chen J, Rathore SS, Radford MJ, et al. Racial differences in the use of cardiac catheterization after acute myocardial infarction. N Engl J Med. 2001;344:1443-1449.
11. Freund KM, Jacobs AK, Pechacek JA, et al. Disparities by race, ethnicity, and sex in treating acute coronary syndromes. J Womens Health. 2012;21: 126-132.

12. Cram $P$, Bayman $L$, Popescu I, et al. Racial disparities in revascularization rates among patients with similar insurance coverage. J Natl Med Assoc. 2009;101:1132-1139.

13. Albert MA, Ayanian JZ, Silbaugh TS, et al. Early results of Massachusetts health care reform on racial, ethnic and socioeconomic disparities in cardiovascular care. Circulation. 2014;129:2528-2538.

14. Farmer SA, Kirkpatrick JN, Heidenreich PA, et al. Ethnic and racial disparities in cardiac resynchronization therapy. Heart Rhythm. 2009;6:325-331.

15. Li S, Chen A, Mead K. Racial disparities in the use of cardiac revascularization: does local hospital capacity matter? PLoS One. 2013;8:e69855.

16. Mukamel DB, Weimer DL, Buchmueller TC, et al. Changes in racial disparities in access to coronary artery bypass grafting surgery between the late 1990s and early 2000s. Med Care. 2007;45:664-671.

17. Cruz Rodriguez B, Acharya P, Salazar-Fields C, et al. Comparison of frequency of referral to cardiotharcic surgery for aortic valve disease in blacks, hispanics and whites. Am J Cardiol 2017: 450-455.

18. Yankey G, Samad Z, Wu A, et al. Aortic valve replacement and outcomes in patients with severe aortic stenosis: is it black or white? J Am Coll Cardiol. 2018;71(11 Suppl) [Epub ahead of print]; DOI: 10.1016/S07351097(18)32551-8.

19. Yeung M, Kerrigan J, Sodhi S, et al. Racial differences in rates of aortic valve replacement in patients with severe aortic stenosis. Am J Cardiol. 2013;112:991-995

20. Sleder A, Tackett S, Cerasale M, et al. Socioeconomic and racial disparities: a case-control study of patients receiving transcatheter aortic valve replacement for severe aortic stenosis. J Racial Ethn Health Disparities. 2016:4:1189-1194.

21. Holmes DR, Jr., Nishimura RA, Grover FL, et al. Annual outcomes with transcatheter valve therapy: from the STS/ACC TVT registry. J Am Coll Cardiol. 2015;66:2813-2823.

22. Minha SA, Barbash IM, Magalhaes MA, et al. Outcome comparison of African-American and caucasian patients with severe aortic stenosis subjected to transcatheter aortic valve replacement: a single-center experience. Catheter Cardiovasc Interv. 2015;85:640-647.

23. Research Data Assistance Center (ResDAC). CCW Technical Guidance: Calculating Medicare Population Statistics. Minneapolis, MN: ResDAC 2018.

24. US Dept of Health and Human Services. Table I.2 Medicare enrollment/ coverage. In: 2013 CMS Statistics. Edited by Department of Health and Human Services. Washington, DC: Centers for Medicare and Medicaid Services, 2013, p. 6.

25. US Dept of Health and Human Services. Table I.2 Medicare enrollment/ coverage. In: 2014 CMS Statistics. Edited by Department of Health and Human Services. Washington, DC: Centers for Medicare and Medicaid Services, 2014, p. 6.

26. Agency for Healthcare Research and Quality. 2016 National Healthcare Quality and Disparities Report. Rockville, MD: Agency for Healthcare Research and Quality, 2016.

27. Goodfellow A, Ulloa JG, Dowling PT, et al. Predictors of primary care physician practice location in underserved urban and rural areas in the United States: a systematic literature review. Acad Med 2016;91:13131321.

28. Thornton RL, Powe NR, Roter D, et al. Patient-physician social concordance, medical visit communication and patients' perceptions of health care quality. Patient Educ Couns. 2011;85:201-208.

29. US Dept of Health and Human Services. Chronic conditions data warehouse. Available at https://www.ccwdata.org/web/guest/conditioncategories Accessed December 19, 2018.

30. Boston Scientific (ed.). 2014 Procedural Reimbursement Guide. Select Percutaneous Coronary Interventions. Boston, MA: Boston Scientific, 2014.

Cite this article as: Pegus C, Duncan I, Greener J, Granada JF, Ahmed T (2018) Achieving health equity by normalizing cardiac care, Health Equity 2:1, 404-411, DOI: 10.1089/heq.2018.0067. 


$\begin{aligned} & \text { Abbreviations Used } \\ & \mathrm{ABC}=\text { Association of Black Cardiologists } \\ & \mathrm{ACC}=\text { American College of Cardiology } \\ & \mathrm{AHA}=\text { American Hospital Association } \\ & \mathrm{AMI}=\text { acute myocardial infarction } \\ & \mathrm{APC}=\text { ambulatory payment classification } \\ & \mathrm{AVD}=\text { aortic valve disease } \\ & \mathrm{AVR}=\text { aortic valve replacement } \\ & \mathrm{CMS}=\text { Centers for Medicare and Medicaid Services } \\ & \mathrm{CPT}-4=\text { Current Procedural Terminology, 4th Edition } \\ & \mathrm{CRF}=\text { Cardiovascular Research Foundation } \\ & \mathrm{CVD}=\text { cardio-vascular disease }\end{aligned}$

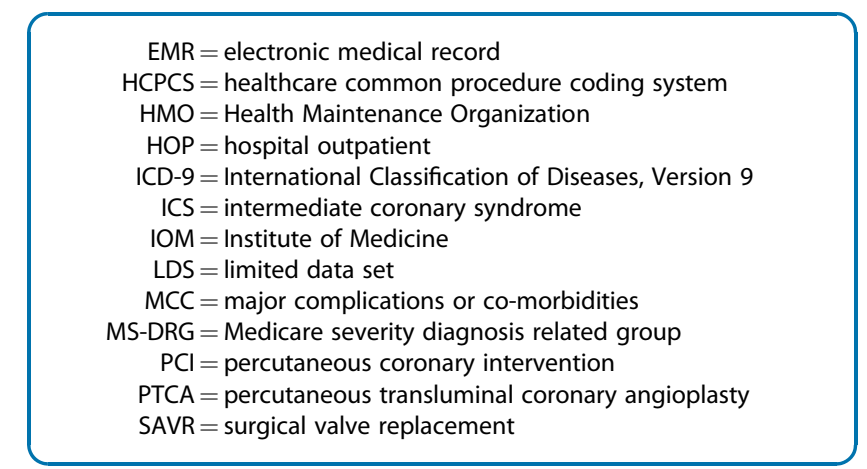

\section{APPENDIX}

Appendix A1. Disease Identification Algorithm

\begin{tabular}{|c|c|c|c|}
\hline Disease algorithms & $\begin{array}{l}\text { Reference } \\
\text { period (years) }\end{array}$ & ICD-9/CPT4/HCPCS codes & Number/types of claims to qualify \\
\hline Acute myocardial infarction (AMI) & 1 & $\begin{array}{c}\text { DX } 410.01,410.11,410.21,410.31,410.41 \\
410.51,410.61,410.71,410.81,410.91 \\
\text { (ONLY first or second Dx on the claim) }\end{array}$ & At least one inpatient claim with Dx code \\
\hline Aortic valve disease ${ }^{3}$ (AVD) & 2 & $\begin{array}{l}\text { 424.1, 396.0, 396.1, 396.2, 396.3, 396.8, } \\
\text { 396.9, 746.3, 746.4, 395.0, 395.2, 395.1, } \\
\text { and } 395.9 \text { (any Dx on the claim) }\end{array}$ & $\begin{array}{l}\text { At least one inpatient, HOP or Carrier } \\
\text { claim with Dx code }\end{array}$ \\
\hline $\begin{array}{l}\text { Intermediate coronary } \\
\text { syndrome (ICS) }\end{array}$ & 2 & 411.1 (any Dx on the claim) & $\begin{array}{l}\text { At least } 1 \text { inpatient, HOP or Carrier } \\
\text { claim with Dx code }\end{array}$ \\
\hline
\end{tabular}

Source: CMS Chronic Conditions Data Warehouse (CCW). ${ }^{29}$

ICD-9, International Classification of Diseases, Version 9; CPT4, Current Procedural Terminonlogy, 4th edition; HCPCS, health care common procedure coding system; HOP, hospital outpatient.

Appendix A2. Procedure Identification

\begin{tabular}{|c|c|c|c|c|c|}
\hline $\begin{array}{l}\text { CPT/HCPCS } \\
\text { codes }\end{array}$ & Description of CPT/HCPCS codes & $\begin{array}{l}\text { ICD-9-proc } \\
\text { codes }\end{array}$ & $\begin{array}{l}\text { Description of ICD-9- } \\
\text { procedure codes }\end{array}$ & MS-DRG & APC \\
\hline 92920 & $\begin{array}{l}\text { Percutaneous transluminal coronary } \\
\text { angioplasty; single major } \\
\text { coronary artery or branch for } \\
\text { AMI) }\end{array}$ & 00.66 & $\begin{array}{l}\text { Percutaneous } \\
\text { transluminal } \\
\text { coronary } \\
\text { angioplasty }\end{array}$ & $\begin{array}{l}\text { 250: Percutaneous } \\
\text { cardiovascular procedures } \\
\text { without coronary artery } \\
\text { stent with MCC }\end{array}$ & $\begin{array}{l}\text { 83: Coronary angioplasty, } \\
\text { valvuloplasty and } \\
\text { Level I endovascular } \\
\text { Revascularization of } \\
\text { the lower extremity }\end{array}$ \\
\hline 92921 & $\begin{array}{l}\text { Percutaneous transluminal coronary } \\
\text { angioplasty; each additional } \\
\text { branch of a major coronary artery } \\
\text { (list separately in addition to } \\
\text { code for primary procedure) for } \\
\text { AMI) }\end{array}$ & $00: 66$ & Same & Same & Same \\
\hline 92928 & $\begin{array}{l}\text { Percutaneous transcatheter } \\
\text { placement of intracoronary } \\
\text { stent(s), with coronary } \\
\text { angioplasty when performed; } \\
\text { single major coronary artery or } \\
\text { branch for AMI) }\end{array}$ & $\begin{array}{l}\text { 36.06: plus } 00.66 \\
00.40-00.48\end{array}$ & $\begin{array}{l}\text { Insertion of non- } \\
\text { drug-eluting } \\
\text { coronary artery } \\
\text { stent(s) }\end{array}$ & $\begin{array}{l}\text { 248: Percutaneous } \\
\text { cardiovascular proc w } \\
\text { non-drug-eluting stent } \\
\text { with MCC or } 4+\text { vessels/ } \\
\text { stents } \\
\text { 249: Percutaneous } \\
\text { cardiovascular proc. } w \\
\text { non-drug-eluting stent } \\
\text { without MCC }\end{array}$ & $\begin{array}{l}\text { 104: Transcatheter } \\
\text { placement of } \\
\text { Intracoronary stents }\end{array}$ \\
\hline
\end{tabular}


Appendix A2. Continued

\begin{tabular}{|c|c|c|c|c|c|}
\hline $\begin{array}{l}\text { CPT/HCPCS } \\
\text { codes }\end{array}$ & Description of CPT/HCPCS codes & $\begin{array}{l}\text { ICD-9-proc } \\
\text { codes }\end{array}$ & $\begin{array}{l}\text { Description of ICD-9- } \\
\text { procedure codes }\end{array}$ & MS-DRG & APC \\
\hline 92929 & $\begin{array}{l}\text { Percutaneous transcatheter } \\
\text { placement of intracoronary } \\
\text { stent(s), with coronary } \\
\text { angioplasty when performed; } \\
\text { each additional branch of a major } \\
\text { coronary artery (list separately in } \\
\text { addition to code for primary } \\
\text { procedure) for AMI) }\end{array}$ & Same & Same & Same & Same \\
\hline 33361 & $\begin{array}{l}\text { Transcatheter aortic valve } \\
\text { replacement (tavr/tavi) with } \\
\text { prosthetic valve; percutaneous } \\
\text { femoral artery approach for } \\
\text { AoStenosis }\end{array}$ & $\begin{array}{l}35.05 \\
35.09\end{array}$ & $\begin{array}{l}\text { Endovascular } \\
\text { replacement of } \\
\text { aortic valve, } \\
\text { Endovascular } \\
\text { replacement of } \\
\text { unspecified heart } \\
\text { valve }\end{array}$ & $216-221,237-238$ & \\
\hline 33362 & $\begin{array}{l}\text { Transcatheter aortic valve } \\
\text { replacement (tavr/tavi) with } \\
\text { prosthetic valve; open femoral } \\
\text { artery approach Aostenosis }\end{array}$ & Same & Same & Same & \\
\hline 33363 & $\begin{array}{l}\text { Transcatheter aortic valve } \\
\text { replacement (tavr/tavi) with } \\
\text { prosthetic valve; open axillary } \\
\text { artery approach Aostenosis }\end{array}$ & Same & Same & Same & \\
\hline 33364 & $\begin{array}{l}\text { Transcatheter aortic valve } \\
\text { replacement (tavr/tavi) with } \\
\text { prosthetic valve; open iliac artery } \\
\text { approach Aostenosis }\end{array}$ & Same & Same & Same & \\
\hline 33365 & $\begin{array}{l}\text { Transcatheter aortic valve } \\
\text { replacement (tavr/tavi) with } \\
\text { prosthetic valve; transaortic } \\
\text { approach (e.g., median } \\
\text { sternotomy, mediastinotomy) } \\
\text { Aostenosis }\end{array}$ & Same & Same & Same & \\
\hline
\end{tabular}

Source: Boston Scientific. ${ }^{30}$

MS-DRG, Medicare Severity Diagnosis Related Group; APC, ambulatory payment classification; MCC, major complications or co-morbidities.

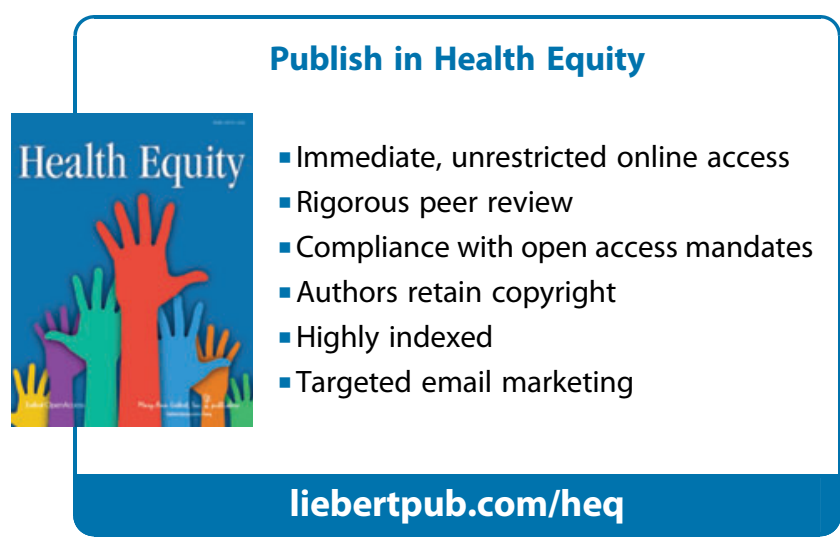

